\title{
Electrocardiographic safety evaluation of extended artemether-lumefantrine treatment in patients with uncomplicated Plasmodium falciparum malaria in Bagamoyo District, Tanzania
}

Lwidiko E. Mhamilawa ${ }^{1,2^{*}}$, Sven Wikström ${ }^{1}$, Bruno P. Mmbando ${ }^{3}$, Billy Ngasala ${ }^{1,2}$ and Andreas Mårtensson ${ }^{1}$

\begin{abstract}
Background: Extended artemisinin-based combination therapy (ACT) for treatment of uncomplicated Plasmodium falciparum malaria with already existing drug regimens, such as artemether-lumefantrine, might be effective in tackling the emerging ACT resistance. However, given the history of cardiotoxicity among anti-malarial drugs structurally similar to lumefantrine, the potential effect of extended artemether-lumefantrine treatment on the electrocardiographic (ECG) QTc interval is of high concern.
\end{abstract}

Methods: Male and non-pregnant females aged 1-65 years, diagnosed with uncomplicated $P$. falciparum malaria in Bagamoyo district, Tanzania, were randomized into two arms. The intervention arm received an extended, i.e. 6-day, course of artemether-lumefantrine and an additional single low-dose primaquine $(0.25 \mathrm{mg} / \mathrm{kg})$ administered together with the last artemether-lumefantrine dose. The control arm received the standard weight-based 3-day course. ECGs were performed at day 0 and $4-5 \mathrm{~h}$ after the last dose at day 5. QT intervals were read manually using the tangent method and automatically. Bazett's (QTcB) and Fridericia's (QTCF) formulae were used for correction for heart rate. Descriptive statistics were used to calculate baseline characteristics and the number of supra-thresholds QTc intervals (QTc prolongation $>500$, change in QTc interval $(\triangle \mathrm{QTC})>60 \mathrm{~ms})$. The mean change in QTc interval in and between the two arms was compared using the paired t-test and independent samples t-test, respectively.

Results: A total of 195 patients were enrolled, 103 and 92 in the intervention and control arm, respectively. No patient experienced QTc intervals $>500 \mathrm{~ms}$ on day 5 by both formulae. Patients with $\triangle \mathrm{QTc}>60 \mathrm{~ms}$, for QTcF were 6/103 (5.8\%) vs 2/92 (2.2\%) and for QTcB 2/103 (1.9\%) vs 1/92 (1.1\%) in the intervention and control arms, respectively. The mean difference in $\triangle \mathrm{QTC}$ interval was statistically significant between the two arms with both correction formulae, $11.4 \mathrm{~ms}(95 \% \mathrm{Cl} 2.7-20.0, \mathrm{p}=0.010)$ and $13.4 \mathrm{~ms}(95 \% \mathrm{Cl} 5.3-21.5, \mathrm{p}=0.001)$, for QTcB and QTcF, respectively.

Conclusion: The extended 6-day course of artemether-lumefantrine did not reveal clinically relevant QTc prolonging effects. However, significant QTcF prolongation and presence of patients with supra-threshold QTc values observed

*Correspondence: Iwidiko.edward@kbh.uu.se

1 Department of Women's and Children's Health, International Maternal

and Child Health (IMCH), Uppsala University, Uppsala, Sweden

Full list of author information is available at the end of the article

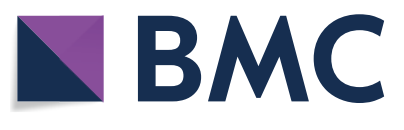

(c) The Author(s) 2020. This article is licensed under a Creative Commons Attribution 4.0 International License, which permits use, sharing, adaptation, distribution and reproduction in any medium or format, as long as you give appropriate credit to the original author(s) and the source, provide a link to the Creative Commons licence, and indicate if changes were made. The images or other third party material in this article are included in the article's Creative Commons licence, unless indicated otherwise in a credit line to the material. If material is not included in the article's Creative Commons licence and your intended use is not permitted by statutory regulation or exceeds the permitted use, you will need to obtain permission directly from the copyright holder. To view a copy of this licence, visit http://creativeco mmons.org/licenses/by/4.0/. The Creative Commons Public Domain Dedication waiver (http://creativecommons.org/publicdomain/ zero/1.0/) applies to the data made available in this article, unless otherwise stated in a credit line to the data. 
in the intervention arm underscore the importance of further monitoring of QTC parameters in extended artemetherlumefantrine treatment.

Trial registration ClinicalTrials.gov, NCT03241901. Registered July 27, 2017. https://clinicaltrials.gov/show/NCT03241901

Keywords: Malaria, Plasmodium falciparum, Cardiotoxicity, Artemether-lumefantrine, Tanzania, Prolonged treatment, Artemisinin resistance, ECG

\section{Background}

Plasmodium falciparum resistance to artemisinin-based combination therapy (ACT) is an emerging threat to the improvements made for past decade in the strive to control and eliminate malaria [1]. Alternative strategies to protect the therapeutic lifespan of artemisinin-based combinations are being explored, such as extending the ACT treatment duration, optimizing drug dosing, new combinations and use of triple ACT as development of new anti-malarial drugs with comparable efficacy is underway [2-6]. Among studies that explored the efficacy and safety of extended ACT, such as artemether-lumefantrine, i.e. the most commonly used artemisinin-based combination for the treatment of uncomplicated $P$. falciparum malaria in Africa, few have electrocardiographic (ECG) parameters as part of safety reporting $[4,6]$.

The QT interval in PQRST complex from an ECG, represents the time for ventricular depolarization and repolarization in the cardio-myocytes and it is correlated with the heart rate; the higher heart rate, the shorter QT interval and vice versa [7]. Because of this, the interpreted QT interval is corrected for the heart rate by various formulae to get a corrected QT interval (QTc). Commonly used formulae are Bazett's (QTcB) and Fridericia's (QTcF) among others $[8,9]$.

The importance of reporting the QTc interval from ECG in studies that involve anti-malarial drugs is anchored in the history of cardiotoxicity among some quinoline anti-malarial and structurally-related medicines [10]. Lumefantrine, the long-acting partner drug in artemether-lumefantrine, has chemical and structural similarities with halofantrine. Halofantrine has curtailed use as an anti-malarial drug since it is known for causing QTc prolongation and sudden cardiac death [11-13]. Studies of anti-malarial drugs that contain quinolines or structurally similar partner drugs have often included prolongation of the QTc as part of ECG evaluations. Prolongation of the QTc interval is a sensitive indicator for the risk of developing serious cardiac arrhythmias like Torsade de Pointes (TdP) and sudden death, albeit not highly specific $[14,15]$.

To date there has been no evidence that artemetherlumefantrine has caused serious cardiac adverse events in malaria patients when given as the standard weight based treatment course, i.e. twice daily, for 3 days (one tablet containing $20 \mathrm{mg}$ artemether and $120 \mathrm{mg}$ lumefantrine) [16-18], or as a single dose in healthy study participants [11]. However, a significant positive relationship between lumefantrine concentration and corrected QT interval by Fridericia's (QTcF) was observed when healthy adults received a standard 6-dose regimen of artemether-lumefantrine over 3 days, in a trial performed by Novartis prior to seeking market approval [19]. Also, a recent clinical trial in Congo reported a statistically significant correlation between the QTcF interval, and the concentration of lumefantrine. The Congo study evaluated the efficacy, safety and tolerability of extending treatment with artemether-lumefantrine for 5 days among pregnant and non-pregnant women with uncomplicated $P$. falciparum malaria [6]. The extended treatment was found to be safe in this study population, and a maximum QTcF interval prolongation of 7.02-8.19 ms was seen. However, in the same study, corrected QT interval by Bazett's (QTcB) did not demonstrate the correlation.

The Bazett's formula is considered to be inferior to Fridericia's in adult populations [20], however, consensus is lacking on which formula is best suited for reporting in paediatric populations [21, 22]. This is reflected in the heterogeneity of measurement methods and correction formulae that have been reported in studies of antimalarial drugs, including customising study specific QT assessment methods which are independent of heart rate $[14,23]$. The importance of continued monitoring of QTc prolonging effects for the new regimens of antimalarial drugs and further evaluation of optimal methods for measuring and reporting the QTc interval should not be underestimated, given the history of cardiotoxicity among anti-malarial drugs.

This study investigated the effects of an extended course (6 days) of artemether-lumefantrine on QTc interval vs the standard (3 days) course in male and non-pregnant female patients with uncomplicated $P$. falciparum malaria in Bagamoyo District, Tanzania, and compared the outcomes between QTcB and QTcF.

\section{Methods}

\section{Study site and population}

This study was part of a clinical trial with the aim of comparing extended 6 days of artemether-lumefantrine vs standard treatment i.e. 3 days course on PCR determined 
parasite clearance, cure rate, post-treatment prophylaxis, and safety and tolerability. Full description and results from the parent study will be reported in a separate publication, but briefly; 280 patients with microscopy confirmed uncomplicated $P$. falciparum malaria were enrolled in Yombo and Fukayosi dispensaries, Bagamoyo District, Tanzania, after giving written informed consent. The study was conducted in accordance with the Declaration of Helsinki and Good Clinical Practice, and was granted ethical approval from the National Institute for Medical Research (NIMR/HQ/R.8a/Vol. IX/2477) and Muhimbili University of Health and Allied Sciences, Tanzania, (MU/DRP/ERP/Vol.IX/174) and the Regional Ethical Review Board, Stockholm, Sweden. The study is registered on https://www.clinicaltrials.gov (NCT03241901).

\section{Inclusion criteria}

Male and non-pregnant female patients were included if they were between 1 and 65 years old, had a weight of $10 \mathrm{~kg}$ and above, body temperature $\geq 37.5{ }^{\circ} \mathrm{C}$ or history of fever within the last $24 \mathrm{~h}$, microscopy determined asexual $P$. falciparum mono-infection (regardless of parasitaemia) and a QTcB interval at baseline ECG $<440 \mathrm{~ms}$ in males and $<460 \mathrm{~ms}$ in females. The QTcB interval used for enrolment was automatically measured value from the ECG machine.

\section{Exclusion criteria}

Patients were excluded from the study in case of any symptoms/signs of severe malaria or other danger signs, pregnancy, breastfeeding or if the patient was unwilling to practice birth control during participation in the study, if they had a known allergy to study medications or known cardiac disorders, $\mathrm{Hb}<8 \mathrm{~g} / \mathrm{dl}$, reported antimalarial intake within 2 weeks, regular medication which may interfere with anti-malarial pharmacokinetics or had received a blood transfusion within the last 90 days.

\section{Study design}

The patients were randomized into control and intervention arms in this open, single-blinded trial. The patients in the control arm received artemether-lumefantrine tablets $(20 / 120 \mathrm{mg})\left(\right.$ Coartem $^{\circledR}$, Novartis Pharma, Switzerland) in accordance with their body weight and the Tanzanian national treatment guidelines for uncomplicated $P$. falciparum malaria, i.e. twice a day for 3 consecutive days, as follows: one tablet to patients weighing $5-14 \mathrm{~kg}$; two tablets to children weighing $15-24 \mathrm{~kg}$; three tablets to children weighing $25-34 \mathrm{~kg}$ and four tablets for patients with a weight above $35 \mathrm{~kg}$. In the intervention arm, patients received artemether-lumefantrine according to the protocol described above for 6 consecutive days. In addition to this, a single dose of $0.25 \mathrm{mg} / \mathrm{kg}$ primaquine (Primaquine phosphate, Sanofi) was given together with the last dose of artemether-lumefantrine as supported by modelling data, which suggest that a later primaquine dose has improved gametocidal effect compared to giving with first dose [24]. ECGs were performed by a qualified physician for both treatment arms, at two time points, i.e. before enrolment and $4-5 \mathrm{~h}$ after the 12th (final) dose of artemether-lumefantrine in the extended treatment arm and at the 12th visit (3 days after the last dose) for the control arm.

\section{QT measurement method and QT correction for heart rate}

Standard 12-lead ECGs were recorded at speed of $25 \mathrm{~mm} / \mathrm{s}$ and amplitude of $10 \mathrm{mV} / \mathrm{mm}$ with two different machines, one from each study site, the Sonoscape ECG IE12 (Shenzhen, China) and CardiMax FX-7402 (Fukuda Denshi USA). The interval between one $\mathrm{R}$ wave and the next (RR intervals) in an ECG, were derived from the heart rate values, which were measured automatically by the machines.

In addition to the automatically obtained values, manual measurement using the tangent method was performed by a single analyst blinded to treatment arm. Prominent U-waves ( $\geq 50 \%$ of the height of the T-wave) were not included in QT interval, neither were discrete U-waves. Four different values were measured in lead II with a precision of $0.5 \mathrm{~mm}$. If not readable in lead II, the QT interval was measured in the chest leads, preferably V1-V2. The mean of the four QT interval values was taken as final QT interval, then corrected for heart rate with Bazett's $\left(\mathrm{QTcB}=\mathrm{QT} / \mathrm{RR}^{1 / 2}\right)$ and Fridericia's $\left(\mathrm{QTcF}=\mathrm{QT} / \mathrm{RR}^{1 / 3}\right)$ formulae, respectively $[25,26]$. An additional age adjusted QTc interval was generated by combining QTcB of children $<10$ years and QTcF of patients $\geq 10$ years to get a "QTc-age".

Cut-off values of $>500 \mathrm{~ms}$ for QTc prolongation or $>60 \mathrm{~ms}$ for change in QTc ( $\triangle \mathrm{QTC}$ ) interval values from baseline were used to categorize supra-thresholds QTc intervals i.e., QTc intervals exceeding thresholds of clinical concern $[27,28]$.

\section{Other safety parameters}

Haemoglobin concentration was measured during enrolment and at day 7, using a portable spectrophotometer, HemoCue Hb 201+ (HemoCue AB, Ängelholm Sweden). Venous blood $(2 \mathrm{ml})$ was collected during enrolment and at day 7 , to asses liver integrity by alanine aminotransferase (ALAT), aspartate aminotransferase (ASAT), serum bilirubin levels and kidney integrity by creatinine levels. The samples were stored for a maximum of $48 \mathrm{~h}$ in the field refrigerator $\left(4^{\circ} \mathrm{C}\right)$ before transport to an ISO certified reference laboratory at the Bagamoyo Research 
and Training Unit (Ifakara Health Institute) for analysis. The biochemistry analyses were done using COBAS INTEGRA 400 plus (COBAS, USA). The values were compared with age specific normal ranges [29].

\section{Outcomes}

The primary outcomes of this study were to compare (1) the mean change in QTcB and QTcF interval between day 0 and day 5 , and (2) the number of supra-thresholds QTc intervals (i.e. QTc $>500 \mathrm{~ms}$ or $\Delta \mathrm{QTc}>60 \mathrm{~ms}$ ), within and between the arms. Secondary outcomes included investigating the number of QTcB and QTcF intervals exceeding $480 \mathrm{~ms}$, and comparing the performance of Bazett's and Fredericia's formulae in correcting the QT for heart rate.

\section{Statistical analysis}

Descriptive statistics were used to summarize weight, age, heart rate and body temperature for the patients at baseline and supra-thresholds QTc intervals. Changes in mean QTc interval from baseline and the last measurement for both correction formulae and QTc-age were compared by using paired $t$-test. Mean changes in QTc interval between day 0 and 5 were compared between the treatment arms with the independent sample t-test.
Bazett's and Fridericia's formulae were used in correction of heart rate. An attempt to assess the mean change in QTc independently from correction formulae and heart rate changes was done by analysing the intercepts of $\Delta \mathrm{QTC}$ vs $\Delta \mathrm{RR}$ regression. Changes in heart rates and body temperature between the two time-points were calculated with the paired t-test. QTc values for both correction formulae and QTc-age were plotted against the $R R$ intervals superimposed with a line of best fit from a linear regression model. A p-value $<0.05$ was considered statistically significant. All statistical analyses were made in IBM SPSS statistics (version 26.0. Armonk, NY: IBM Corp).

\section{Results}

Patient flow and demographic data

The flow of patients through the ECG safety evaluation study is presented in Fig. 1. A total of 195/280 patients were eventually included in the study. Baseline clinical and demographic characteristics were comparable between the treatment arms (Table 1). The mean age in the group of excluded patients was significantly lower $(p=0.047)$ than the mean age among the included patients (11.6 compared to 15.0 years). On average, heart

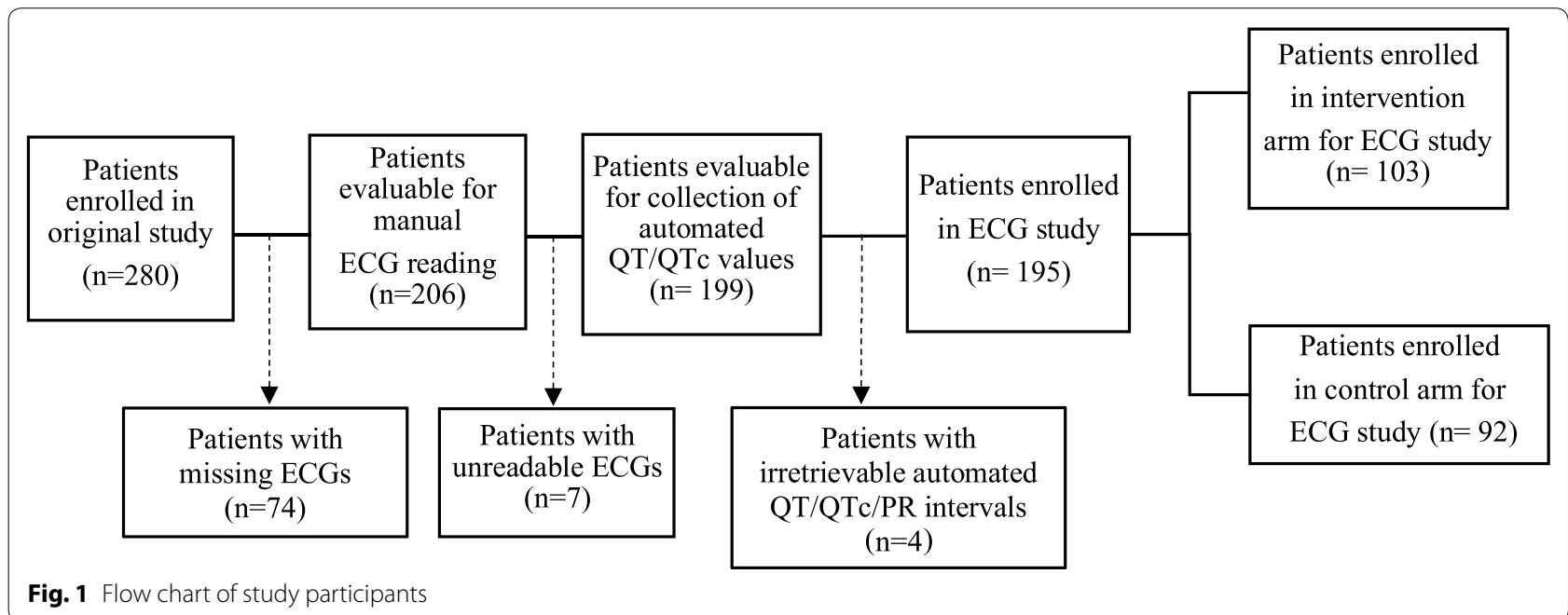

Table 1 Baseline characteristics of included patients

\begin{tabular}{llll}
\hline & Intervention arm $(\mathbf{n}=103)$ & Control arm $(\mathbf{n}=\mathbf{9 2})$ & P value \\
\hline Age (years) & $11.0(6.0-14.0)$ & $12(6.3-26.5)$ & $0.284^{\dagger}$ \\
Sex, female; male & $48 ; 55$ & $37 ; 55$ & $0.389^{\ddagger}$ \\
Weight $(\mathrm{kg})$ & $28.0(20.0-45.0)$ & $29.5(20.3-54.3)$ & $0.952^{\dagger}$ \\
Temperature $\left({ }^{\circ} \mathrm{C}\right)$ & $38.4(37.7-39.2)$ & $38.4(37.7-39.1)$ & $0.965^{\dagger}$ \\
\hline
\end{tabular}

Data are medians (interquartile range)

+ Non parametric independent samples median test

¥ Fisher's exact test 
Table 2 Heart rate data

\begin{tabular}{|c|c|c|c|}
\hline & $\begin{array}{l}\text { Intervention } \\
\text { arm }(n=103)\end{array}$ & Control arm $(n=92)$ & Pvalue $^{\dagger}$ \\
\hline Mean heart rate day 0 & $105.5(23.7)$ & $101.7(24.6)$ & 0.708 \\
\hline Mean heart rate day 5 & $82.9(16.0)$ & $83.8(17.0)$ & 0.284 \\
\hline $\begin{array}{l}\text { Mean change in heart } \\
\text { rate between day } 0 \\
\text { and } 5\end{array}$ & $-22.5(18.8)$ & $-18.0(19.3)$ & 0.095 \\
\hline P value & $<0.001$ & $<0.001$ & \\
\hline
\end{tabular}

Heart rate values were measured in BPM (beats per minute). Data are means (standard deviation)

Italic values indicate significance of $p$ value $(p<0.05)$

$+P$ value was compared using the independent $t$-test for difference in the mean change in heart rate and mean heart rate between the treatment arms in respective time-points

$¥ \mathrm{P}$ value was compared using paired t-test for difference in mean heart rate within the treatment arms between day 0 and 5

Table 3 Body temperature data

\begin{tabular}{llll}
\hline & $\begin{array}{c}\text { Intervention } \\
\text { arm }(\mathbf{n = 1 0 3})\end{array}$ & Control arm (n=92) & P value $^{\dagger}$ \\
\hline $\begin{array}{l}\text { Mean temperature } \\
\text { day 0 }\end{array}$ & $38.4(1.0)$ & $38.3(1.0)$ & 0.542 \\
$\begin{array}{l}\text { Mean temperature } \\
\text { day 5 }\end{array}$ & $36.7(0.3)$ & $36.7(0.3)$ & 0.474 \\
$\begin{array}{l}\text { Mean change in tem- } \\
\text { perature between } \\
\text { day 0 and 5 }\end{array}$ & $-1.7(1.1)$ & $-1.6(1.0)$ & 0.419 \\
$\begin{array}{l}\text { P value } \\
\text { val }\end{array}$ & $<0.001$ & $<0.001$ &
\end{tabular}

Body temperature values were measured in ${ }^{\circ} \mathrm{C}$ (degrees Celsius). Data are means (standard deviation)

Italic values indicate significance of $p$ value $(p<0.05)$

${ }^{+} \mathrm{P}$ values were compared using the independent $t$-test for difference in the mean change in body temperature and mean body temperature between the treatment arms in respective time-points

* $\mathrm{P}$ values were compared using paired $\mathrm{t}$-test for difference in mean body temperature within the treatment arms between day 0 and 5 rate decreased by $20.4 \mathrm{bpm}$ between day 0 and day 5 . There was no statistically significant difference between the intervention and control arm in mean change in heart rate between day 0 and day 5 . Heart rate data are shown in Table 2.

There was no statistically significant difference in body temperature or mean change in body temperature between the two arms. A statistically significant decrease of $1.7^{\circ} \mathrm{C}$ and $1.6{ }^{\circ} \mathrm{C}$ was seen in the intervention and control arm, respectively. Serial body temperature data are presented in Table 3.

\section{QTc data}

Compared to the baseline, there was a statistically significant increase of the mean QTcF interval by $16.2 \mathrm{~ms}$ $(\mathrm{p}<0.001)$ in day 5 in the intervention arm, while there was no significant difference in the same period when using Bazett's formula in the intervention arm. In the control arm, a significant change $(p=0.004)$ was observed when correction by Bazett's was used (Table 4). Generally, the QTc values obtained with Bazett's correction formula were higher than the intervals corrected for heart rate with Fridericia's formula.

\section{Comparison of mean QTc change between treatment arms} There was a statistically significant difference in mean QTc change between the intervention and control arm with both correction formulae, $11.4 \mathrm{~ms}$ for QTcB and 13.4 for QTcF, respectively (Table 5). The difference existed also when analysing the automatically obtained data, with a mean QTcB change of $9.5 \mathrm{~ms}(\mathrm{p}=0.006)$. Table 6 presents resuts of comparing intercept of the $\triangle \mathrm{QTC}$ vs $\Delta \mathrm{RR}$ as mean (SD) of each arm for different QT correction formulae, which was statistically significant different between arms. There was no statistically

Table 4 ECG data

\begin{tabular}{|c|c|c|c|c|c|c|c|c|}
\hline \multirow[t]{2}{*}{ Arm } & \multirow[t]{2}{*}{ Correction formula } & \multirow[t]{2}{*}{ Day } & \multirow{2}{*}{$\begin{array}{l}\text { QTc (ms) } \\
\text { Mean QTc (SD) }\end{array}$} & \multicolumn{2}{|c|}{ Absolute QTc prolongation } & \multicolumn{3}{|c|}{ Change from baseline } \\
\hline & & & & $\mathrm{QTc}>480 \mathrm{~ms}$ & $\mathrm{QTc}>500 \mathrm{~ms}$ & $\Delta \mathrm{QTc}>60 \mathrm{~ms}$ & Mean $(95 \% \mathrm{Cl})$ & P value* \\
\hline \multirow[t]{6}{*}{ Intervention $(n=103)$} & Bazett's & 0 & $410.2(25.4)$ & 1 & 1 & 1 & $1.9(-3.9-7.8)$ & 0.513 \\
\hline & & 5 & $412.1(25.0)$ & 0 & 0 & & & \\
\hline & Fridericia's & 0 & $375.3(26.0)$ & 0 & 0 & 6 & $16.2(10.6-21.7)$ & $<0.001$ \\
\hline & & 5 & $391.5(21.2)$ & 0 & 0 & & & \\
\hline & QTc-age & 0 & $393.4(31.2)$ & 0 & 0 & 4 & $9.1(3.2-15.0)$ & 0.003 \\
\hline & & 5 & $402.5(25.7)$ & 0 & 0 & & & \\
\hline \multirow[t]{6}{*}{ Control $(n=92)$} & Bazett's & 0 & $416.8(32.1)$ & 4 & 1 & 1 & $-9.4(-15.8-(-3.0)$ & 0.004 \\
\hline & & 5 & $407.4(27.5)$ & 1 & 0 & & & \\
\hline & Fridericia's & 0 & $383.6(30.2)$ & 1 & 0 & 2 & $2.7(-3.3-8.8)$ & 0.371 \\
\hline & & 5 & $386.3(23.4)$ & 0 & 0 & & & \\
\hline & QTc-age & 0 & $400.9(35.2)$ & 2 & 1 & 1 & $-3.0(-9.7-3.6)$ & 0.367 \\
\hline & & 5 & $397.9(27.7)$ & 0 & 0 & & & \\
\hline
\end{tabular}

Italic values indicate significance of $p$ value $(p<0.05)$

* P values were calculated using the paired t-test for change in mean QTC interval between day 0 and 5 in each treatment arm with Bazett's and Fridericia's formulae and age adjusted QTc values (QTc-age), respectively. All QT intervals were manually derived 
Table 5 Mean QTc change between treatment arms

\begin{tabular}{lcccccr}
\hline & $\begin{array}{l}\text { Intervention arm } \\
(\mathbf{n}=\mathbf{1 0 3})\end{array}$ & Control arm $(\mathbf{n}=\mathbf{9 2})$ & Mean difference & $\mathbf{9 5 \%} \mathbf{C l}$ & P value* $^{*}$ & All patients $(\mathbf{n}=\mathbf{1 9 5})$ \\
\hline$\triangle \mathrm{QTCB}^{\psi}$ & $1.9(30.1)$ & $-9.4(30.9)$ & 11.4 & $2.7-20.0$ & 0.010 & $-3.4(30.9)$ \\
$\Delta \mathrm{QTCF}^{\psi}$ & $16.2(28.2)$ & $2.7(29.1)$ & 13.4 & $5.3-21.5$ & 0.001 & $9.8(29.3)$ \\
$\Delta \mathrm{QTCB}^{*}$ & $3.1(22.1)$ & $-6.4(25.6)$ & 9.5 & $2.7-16.2$ & 0.006 & $-1.4(24.2)$ \\
\hline
\end{tabular}

Data are means (standard deviation). Values are reported in milliseconds

Italic values indicate significance of $p$ value $(p<0.05)$

* $\mathrm{P}$ values were calculated using the independent $\mathrm{t}$-test for difference in mean change in QTc interval between the treatment arms

$\Psi$ Manually measured data

* Automatically obtained data from machine

Table 6 Comparing intercept of the $\Delta Q T$ C vs $\Delta R R$ as mean (SD) between arms for each formulae

\begin{tabular}{llcll}
\hline Correction formulae & Arm & Mean (SD) & $\mathbf{9 5 \%} \mathrm{Cl}$ & P-value* $^{*}$ \\
\hline Bazett's & Intervention & $10.6(38.6)$ & $3.2-18.1$ & 0.014 \\
& Control & $-2.4(35.0)$ & $-9.6-4.8$ & \\
Fridericia's & Intervention & $11.1(36.5)$ & $3.9-18.3$ & 0.014 \\
& Control & $-1.3(33.6)$ & $-8.2-5.6$ & \\
QTc-age & Intervention & $10.5(38.4)$ & $3.0-18$ & 0.022 \\
& Control & $-1.9(36.5)$ & $-9.5-5.7$ &
\end{tabular}

Italic values indicate significance of $p$ value $(p<0.05)$

* $P$ values were calculated using the t-test for comparing the means of mean change in QTc interval between day 0 and 5 in each treatment arm

significant difference between the manually and automatically obtained data, when comparing mean QTcB change in all patients.

In terms of supra-threshold intervals, no QTc interval exceeded $500 \mathrm{~ms}$ in either of the arms with Fridericia's formula. However, one patient from each arm had QTcB interval exceeding this threshold. Importantly, in both cases this occurred prior to treatment initiation (day $0)$. One patient in the control arm exceeded the lower threshold (QTc $>480 \mathrm{~ms}$ ) on day 5 when using Bazett's formula, whilst no patient in the intervention arm did. With Fridericia's formula 6/103 (5.8\%) patients in the intervention arm had a QTc lengthening of more than $60 \mathrm{~ms}$, as compared with $2 / 92(2.2 \%)$ in the control arm. With Bazett's formula, the number was $2 / 103$ (1.9\%) in the intervention arm and 1/92 (1.1\%) in the control arm. Individual data on patients with a QTc prolongation of more than $60 \mathrm{~ms}$ are shown in Additional file 1: Table S1.

\section{QTc/RR regression}

QTc values were plotted against the RR intervals (Fig. 2). The plot shows that QTcB decreased as RR interval increased while QTcF increased as RR interval increased. The plot with QTc-age demonstrated an improved independence to RR interval with an $\mathrm{R}^{2}$ value of 0.007 of the regression lines. The slopes $(95 \% \mathrm{CI})$ of the regression lines of QTcB, QTcF and QTc-age was - $0.049(-0.065-$ $(-0.033)), 0.046(0.030-0.061)$ and $-0.015(-0.033-$ $0.003)$, respectively.

\section{Discussion}

Safety

Previous studies have shown that WHO approved therapeutic doses of artemisinin-based combination can prolong the QTc interval in patients treated for uncomplicated $P$. falciparum malaria, but without causing arrhythmias or sudden deaths secondary to cardiac manifestations associated with ACT [15, 23]. In this study, prolonging treatment with artemether-lumefantrine for a total of 6 days, together with a single low dose of primaquine was found to be safe with no patients experiencing any cardiac adverse events. There were no patients in this study with QTc intervals $>500 \mathrm{~ms}$ on day 5 , and only 6/103 (5.8\%) (QTcF) and 2/103 (1.9\%) (QTcB) patients had individual $\Delta \mathrm{QTC}>60 \mathrm{~ms}$ in the intervention arm. This proportion of patients with a $\Delta \mathrm{QTC}>60 \mathrm{~ms}$, is comparable to previous results from studies of standard weight-based 3 days artemether-lumefantrine treatment in African children [17]. Interestingly, and similarly with these data, the amount of patients with a QTc change from baseline $>60 \mathrm{~ms}$ was higher with Fridericia's formula compared to Bazett's [17]. This might be explained by an inherent tendency of overcorrection at high heart rates and under correction at low heart rates that occurs with Bazett's formula.

It is important to note that none of the patients had risk factors that would have predisposed them to prolonged QTc interval, such as renal impairment (that would have deranged the electrolytes), hepatic impairment, concomitant medication with proarrhythmic effects, or know pre-existing cardiac conditions [30]. Moreover, significant myocardial dysfunction and arrhythmias are rarely seen even in severe malaria cases, and it has been argued that electrocardiographic monitoring for patients with malaria infection may be of questionable clinical value if the purpose is not to 

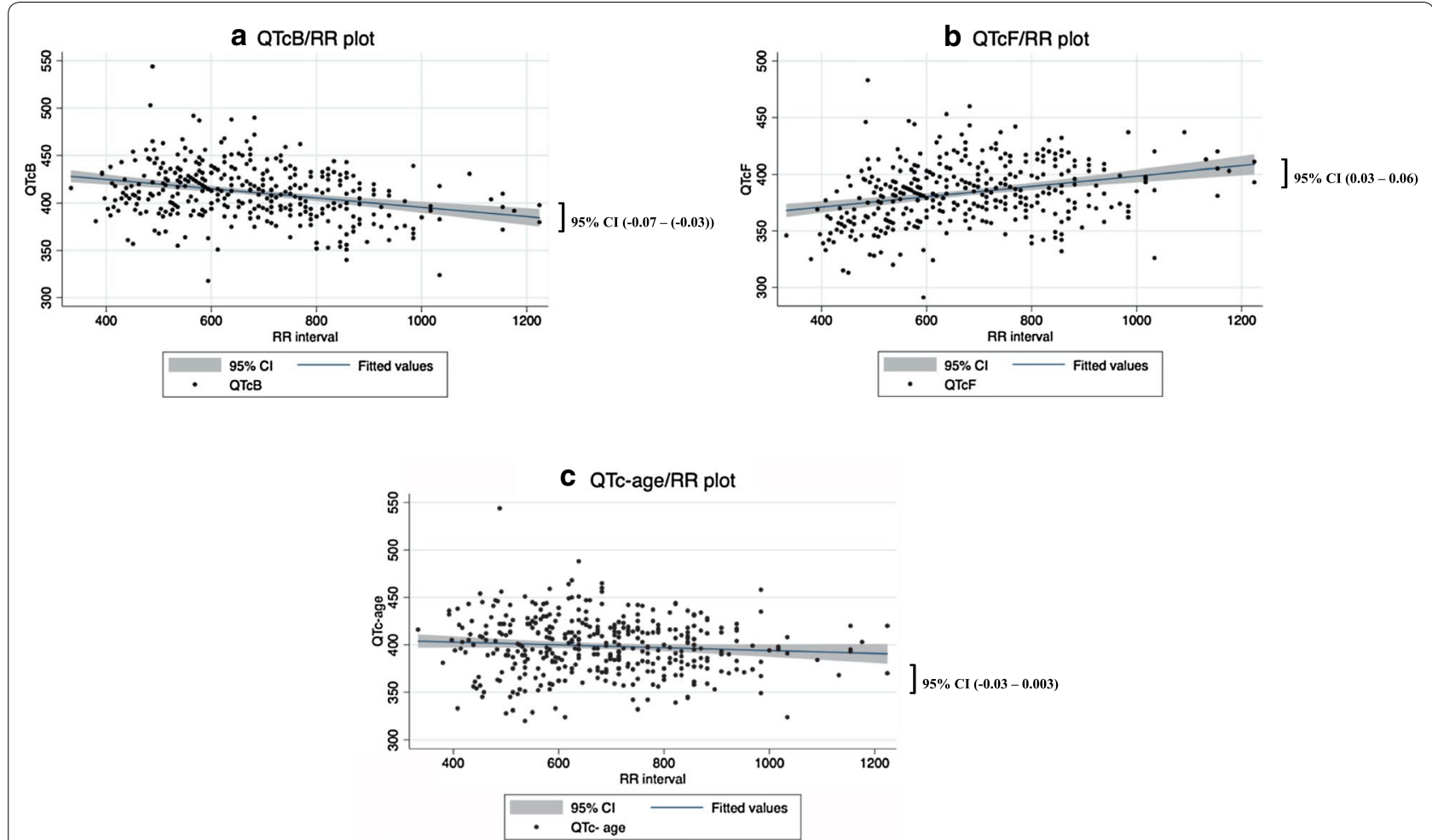

Fig. 2 a QTCB/RR plot, b QTCF/RR plot, c QTc-age/RR plot superimposed with line of best fit from linear regression

study potential drug induced cardiotoxicity [31, 32]. However, one of the main findings of this study was the significant lengthening of the QTcF interval of $16.2 \mathrm{~ms}$ in the intervention arm $(\mathrm{p}<0.001)$. This prolongation is comparable with some previous literature for artemether-lumefantrine [23], and it is even longer when compared to other literatures $[6,19,33]$. No statistically significant QTc prolongation was seen with Bazett's formula in the same treatment arm.

The significant mean difference in mean QTc change between the two arms, $11.4 \mathrm{~ms}$ and $13.4 \mathrm{~ms}$ with Bazett's and Fridericia's formula, respectively, might be related to differences in lumefantrine exposure, where the intervention arm received twice the amount of lumefantrine compared with the control arm, and also at the time of measurement of QTc values in the control arm, it was 3 days past the last artemether lumefantrine dose. In the Novartis safety trial for artemether-lumefantrine given therapeutic doses, a model predicted lumefantrine Cmax of $480 \mathrm{mg}$ correlated with prolongation in mean change in QTcF of $7.0 \mathrm{~ms}$ (90\% CI, $5.5-8.5)$ [19]. In this study the observed QTcF prolongation $(16.2 \mathrm{~ms})$ was almost as twice as the model predicted for Novartis therapeutic doses in the intervention arm who received double the lumefantrine exposure. Not having individual pharmacokinetics data in this study, limits the precision of the comparison.

Recently an extensive systematic review and meta-analysis of factors affecting QT interval in malaria patients and healthy individuals was published, involving more than 10,452 individuals $(93.6 \%$ had microscopy confirmed Plasmodium falciparum or Plasmodium vivax infection). It provided compelling evidence of the contribution of malaria disease severity, changes in heart rate and body temperature in affecting the QT interval during recovery phase, where fever has an effect independent of heart rate. This brings to light the importance of taking into account disease process and other factors like age and sex when evaluating the effects of the anti-malarial drugs (quinolines) or other important medications on QT interval. By doing so, it may be possible to avoid unnecessary withdrawal of potent anti-malarial drugs currently used in malaria case management, or unnecessary discontinuation of anti-malarial drug development because of excessive attribution the QT prolonging effects of the drugs [34].

\section{Correction formulae}

There was no significant difference between the manually and automatically obtained QTcB intervals, which together with the large number of study participants 
suggests that the estimated QT intervals are quite representative of the true QT intervals. Bazett's formula can be used in similar studies for comparisons with historical data, but the QTcB intervals should probably be interpreted with caution compared to QTcF intervals due to its known limitations for adult populations. As expected, when QTc intervals were plotted against RR inter$\mathrm{val}$, there was an overcorrection at high heart rates and under-correction at low heart rates with Bazett's formula (Fig. 2). The regression slopes were generally in line with previous results [35], although the QTcF slope reveals an under-correction at high heart rates and overcorrection at low heart rates. When study specific age adjustments were made (QTc-age) to analyse individual data, the effect of heart rate on QTc interval was reduced. The 95\%CI of the slopes of regression lines differ from zero for Fridericia and Bazett regression but not for QTc-age. This provides a potentially useful method of presenting individual QTc data that is not influenced by the change in heart rate, reducing the limitations observed under the Bazett and Fridericia methods in this population with high range in patient ages.

Moreover, the analysis method of comparing the intercept of $\Delta \mathrm{QTC}$ vs $\Delta \mathrm{RR}$ regression between the groups as mean change of QTc that is independent of the differences between Bazett and Fridericia, provided relatively consistent results across the formulae (Table 6). This important finding is supportive of the robustness of the approach when it comes to harmonizing the formulae dependent discrepancies during analysis of QTc interval for mean (SD) change in QTc as was observed in Table 4. However, this methodology limits assessment of individual values of QTc. Generally results are in line with previous studies that recommended the approach of using study specific adjustments for appropriate estimations of QTc parameters [21, 22].

\section{Study limitations and potential confounders}

With an ECG recording speed of $25 \mathrm{~mm} / \mathrm{s}$, as in this study, the reading precision might be lower than with a recording speed of $50 \mathrm{~mm} / \mathrm{s}$. Therefore, a reading precision of $0.5 \mathrm{~mm}$ was chosen. Also, cut-off thresholds were chosen with this in mind. Cut-off values differ between studies, but there's consensus regarding some thresholds of absolute clinical concern, which were chosen for this study (QTc interval $>500 \mathrm{~ms}, \Delta \mathrm{QTc}>60 \mathrm{~ms}$ ) [28]. There has been concern regarding non QT experts' ability to correctly identify a prolonged QTc interval [36]. However, the QT defining method used in this study (the tangent method) has been shown to be accurate when performed by non QT experts [37].

For a fully accurate comparison between the two arms to be made, ECG recordings obtained at the estimated peak drug concentration in the control arm (4-5 h after the last and 6th dose) would be of high value. Due to the setting of this sub study, and prior studies of the effects on QTc interval from the standard weight based 3-day course of artemether-lumefantrine [6], ECG recordings on day 2 were not performed. The absence of this data curbs the comparisons of absolute QTc interval prolongation between the two arms and constitutes an apparent limitation of this study. Also, in the intervention arm, potential drug-drug interaction due to the addition of single low-dose primaquine calls for cautious interpretation of the observed QTc prolongation. Primaquine is a quinoline which is structurally similar to lumefantrine.

Moreover, the disease process can be a potential confounder in the study. Patients with acute uncomplicated $P$. falciparum infection often experience fever and anxiety, which contribute in sympathetic activation and increased heart rate, leading to shorter RR interval and subsequent relatively shorter QTc interval. With appropriate treatment these symptoms decrease, and the QTc interval lengthens $[10,14,38]$. This poses a potential limitation when it comes to measuring potential QTc prolonging effects from therapeutic drugs, since no correction formula is totally independent of heart rate, and the changes in heart rate before and after treatment makes it more difficult to separate the drug effect on the QTc interval from the effects due to regression of symptoms [23].

The sample size for this sub study was calculated for primary outcomes of the parent study where overall safety assessment was done, but not primarily powered according to ECG parameters.

\section{Conclusion}

The extended 6-day course of artemether-lumefantrine for patients diagnosed with uncomplicated $P$. falciparum malaria in Bagamoyo District, Tanzania, did not have a clinically relevant effect on the QTc interval. However, the significant QTcF prolongation and presence of patients with supra-threshold QTc values observed in the intervention arm underscore the importance of further monitoring of QTc parameters in extended artemetherlumefantrine treatment studies.

\section{Supplementary information}

Supplementary information accompanies this paper at https://doi. org/10.1186/s12936-020-03309-2.

Additional file 1: Table S1. Patients with QTc prolongation > 60 ms from baseline.

Abbreviations

ACT: Artemisinin-based combination therapy; BPM: Beats per minute; Cl: Confidence interval; ECG: Electrocardiogram; FDA: United States Food and Drug 
Administration; IQR: Inter quartile range; ICH: International Conference on Harmonisation of Technical Requirements for Registration of Pharmaceuticals for Human Use; Kg: kilograms; ms: milliseconds; MUHAS: Muhimbili University of Health and Allied Sciences; NIMR: National Institute for Medical Research; QTCB-interval: QT-interval corrected for heart rate with Bazett's formula; QTCF-interval: QT-interval corrected for heart rate with Fridericia's formula; QTc-interval: QT-interval corrected for heart rate; SD: Standard deviation; TdP. Torsade de Pointes; WHO: World Health Organization.

\section{Acknowledgements}

We would like to thank all study participants, village leaders, health care workers at Yombo and Fukayosi, and Bagamoyo Research and Training Unit (Ifakara Health Institute) employees for their dedicated participation in the study. We would also like to acknowledge Dr. Stefan Lönnerholm, for important inputs and a valuable introduction to ECG reading, also Associate Professor of Cardiology Börje Darpö, MD, for support, and much appreciated sharing of knowledge.

\section{Authors' contributions}

LEM, BN, and AM participated in the study design and supervised the field implementation and data/sample collection. SW, LEM, AM, BN, and BPM analysed the data and interpreted the findings. SW and LEM wrote the manuscript assisted by AM, BN, and BPM. All authors read and approved the final manuscript.

\section{Funding}

Financial support was provided by the Swedish Research Council [Grant number: 2016-0577], Swedish International Development Agency [Bilateral Sida Grant: Bil-Tz 16/9875007059] and Uppsala University. The funding bodies did not have any role in the study design, data collection, analysis, data interpretations and manuscript writing. Open access funding provided by Uppsala University.

\section{Availability of data and materials}

The datasets analysed during the current study are available from the corresponding author on reasonable request.

\section{Ethics approval and consent to participate}

The study was conducted in accordance with the Declaration of Helsinki on Good Clinical Practice and received ethical clearance from the National Institute for Medical Research (NIMR/HQ/R.8a/Nol.IX/2477) and Muhimbili University of Health and Allied Sciences, Tanzania, (MU/DRP/ERP/Nol.IX/174) and the Regional Ethical Review Board, Stockholm, Sweden. Written informed consent and ascent was provided by all study participants, in case of children under 7 years, a proxy consent from a parent/legal guardian was obtained. The study is registered at clinicaltrials.gov (identifier: NCT03241901).

\section{Consent for publication}

Not applicable.

\section{Competing interests}

The authors declare that they have no competing interests.

\section{Author details}

${ }^{1}$ Department of Women's and Children's Health, International Maternal and Child Health (IMCH), Uppsala University, Uppsala, Sweden. ${ }^{2}$ Department of Parasitology and Medical Entomology, Muhimbili University of Health and Allied Sciences, Dar es Salaam, Tanzania. ${ }^{3}$ Tanga Centre, National Institute for Medical Research, Tanga, Tanzania.

Received: 13 February 2020 Accepted: 26 June 2020 Published online: 14 July 2020

\section{References}

1. WHO. World Malaria Report 2019. Geneva: World Health Organization; 2019

2. Verlinden BK, Louw A, Birkholtz L-M. Resisting resistance: is there a solution for malaria? Expert Opin Drug Discov. 2016;11:395-406.
3. Dini S, Zaloumis S, Cao P, Price RN, Fowkes FJl, van der Pluijm RW, et al. Investigating the efficacy of triple artemisinin-based combination therapies for treating Plasmodium falciparum malaria patients using mathematical model. Antimicrob Agents Chemother. 2018;62:e01068-118.

4. Tun KM, Jeeyapant A, Myint AH, Kyaw ZT, Dhorda M, Mukaka M, et al. Effectiveness and safety of 3 and 5 day courses of artemether-lumefantrine for the treatment of uncomplicated falciparum malaria in an area of emerging artemisinin resistance in Myanmar. Malar J. 2018;17:258.

5. Kloprogge F, Workman L, Borrmann S, Tekete M, Lefevre G, Hamed K, et al. Artemether-lumefantrine dosing for malaria treatment in young children and pregnant women: a pharmacokinetic-pharmacodynamic metaanalysis. PLoS Med. 2018;15:e1002579.

6. Onyamboko MA, Hoglund RM, Lee SJ, Kabedi C, Kayembe D, Badjanga BB, et al. A randomized controlled trial of three versus five days artemether-lumefantrine regimen for uncomplicated Plasmodium falciparum treatment in pregnancy in Africa. Antimicrob Agents Chemother. 2020;64:e01140-219.

7. Postema PG, Wilde AAM. The measurement of the QT interval. Curr Cardiol Rev. 2014;10:287-94.

8. Luo S, Michler K, Johnston P, Macfarlane PW. A comparison of commonly used QT correction formulae: the effect of heart rate on the QTc of normal ECGs. J Electrocardiol. 2004;37(Suppl):81-90.

9. Sagie A, Larson MG, Goldberg RJ, Bengtson JR, Levy D. An improved method for adjusting the QT interval for heart rate (the Framingham Heart Study). Am J Cardiol. 1992;70:797-801.

10. White NJ. Cardiotoxicity of antimalarial drugs. Lancet Infect Dis. 2007;7:549-58.

11. Bindschedler M, Lefevre G, Degen P, Sioufi A. Comparison of the cardiac effects of the antimalarial co-artemether and halofantrine in healthy participants. Am J Trop Med Hyg. 2002;66:293-8.

12. Malvy D, Receveur MC, Ozon P, Djossou F, Le Metayer P, Touze JE, et al. Fatal cardiac incident after use of halofantrine. J Travel Med. 2000;7:215-6.

13. Bouchaud O, Imbert $P$, Touze JE, Dodoo ANO, Danis M, Legros F. Fatal cardiotoxicity related to halofantrine: a review based on a worldwide safety data base. Malar J. 2009;8:289.

14. Haeusler IL, Chan XHS, Guerin PJ, White NJ. The arrhythmogenic cardiotoxicity of the quinoline and structurally related antimalarial drugs: a systematic review. BMC Med. 2018;16:200.

15. Chan XHS, Win YN, Mawer LJ, Tan JY, Brugada J, White NJ. Risk of sudden unexplained death after use of dihydroartemisinin 2013; piperaquine for malaria: a systematic review and Bayesian meta-analysis. Lancet Infect Dis. 2018;18:913-23.

16. van Vugt M, Ezzet F, Nosten F, Gathmann I, Wilairatana P, Looareesuwan $\mathrm{S}$, et al. No evidence of cardiotoxicity during antimalarial treatment with artemether-lumefantrine. Am J Trop Med Hyg. 1999;61:964-7.

17. Makanga M, Premji Z, Falade C, Karbwang J, Mueller EA, Andriano K, et al. Efficacy and safety of the six-dose regimen of artemether-lumefantrine in pediatrics with uncomplicated Plasmodium falciparum malaria: a pooled analysis of individual patient data. Am J Trop Med Hyg. 2006;74:991-8.

18. van Agtmael M, Bouchaud O, Malvy D, Delmont J, Danis M, Barette S, et al. The comparative efficacy and tolerability of CGP 56697 (artemether + lumefantrine) versus halofantrine in the treatment of uncomplicated falciparum malaria in travellers returning from the Tropics to The Netherlands and France. Int J Antimicrob Agents. 1999;12:159-69.

19. Novartis Pharmaceutical Coorporation. NDA 22-268 for Coartem Clinical Pharmacology and Biopharmaceutics reviews. 2008;39.

20. International Conference on Harmonization. E14 Implementation Working Group ICH E14 Guideline: The Clinical Evaluation of QT/QTc Interval Prolongation and Proarrhythmic Potential for Non-Antiarrhythmic Drugs Questions \& Answers (R3). Internet. 2015;3:1-18.

21. Wernicke JF, Faries D, Breitung R, Girod D. QT correction methods in children and adolescents. J Cardiovasc Electrophysiol. 2005;16:76-81.

22. Benatar A, Feenstra A. QT correction methods in infants and children: effects of age and gender. Ann Noninvasive Electrocardiol. 2015;20:119-25.

23. Funck-Brentano C, Ouologuem N, Duparc S, Felices M, Sirima SB, Sagara I, et al. Evaluation of the effects on the QT-interval of 4 artemisinin-based combination therapies with a correction-free and heart rate-free method. Sci Rep. 2019;9:883

24. Lawpoolsri S, Klein EY, Singhasivanon P, Yimsamran S, Thanyavanich N Maneeboonyang $\mathrm{W}$, et al. Optimally timing primaquine treatment to 
reduce Plasmodium falciparum transmission in low endemicity ThaiMyanmar border populations. Malar J. 2009;8:159.

25. Bazett HC. An analysis of the time-relations of electrocardiograms. Ann Noninvasive Electrocardiol. 1997;2:177-94.

26. Fridericia LS. Die Systolendauer im Elektrokardiogramm bei normalen Menschen und bei Herzkranken. Acta Med Scand. 1920;53:469-86.

27. ICH. E14 clinical evaluation of QT/QTc interval prolongation and proarrhythmic potential for non-antiarrhythmic drugs. 2005.

28. Trinkley KE, Page RL 2nd, Lien H, Yamanouye K, Tisdale JE. QT interval prolongation and the risk of Torsades de pointes: essentials for clinicians. Curr Med Res Opin. 2013;29:1719-26.

29. Buchanan AM, Fiorillo SP, Omondi MW, Cunningham CK, Crump JA. Establishment of biochemistry reference values for healthy Tanzanian infants, children and adolescents in Kilimanjaro Region. Trop Med Int Health. 2015;20:1569-77.

30. WHO Evidence Review Group. The cardiotoxicity of antimalarial. Geneva, World Health Organization, 2016. https://www.who.int/malaria/mpac/ mpac-mar2017-erg-cardiotoxicity-report-session2.pdf.

31. Wu W, Liang Y, Wu G, Su Y, Zhang H, Zhang Z, et al. Effect of artemisininpiperaquine treatment on the electrocardiogram of malaria patients. Rev Soc Bras Med Trop. 2019;52:e20180453.

32. Bethell DB, Phuong PT, Phuong CX, Nosten F, Waller D, Davis TM, et al. Electrocardiographic monitoring in severe falciparum malaria. Trans R Soc Trop Med Hyg. 1996;90:266-9.

33. Adjei GO, Oduro-Boatey C, Rodrigues OP, Hoegberg LC, Alifrangis M, Kurtzhals JA, et al. Electrocardiographic study in Ghanaian children with uncomplicated malaria, treated with artesunate-amodiaquine or artemether-lumefantrine. Malar J. 2012;11:420.
34. Chan XHS, Win YN, Haeusler IL, Tan JY, Loganathan S, Saralamba S, et al. Factors affecting the electrocardiographic QT interval in malaria: a systematic review and meta-analysis of individual patient data. PLoS Med. 2020;17:e1003040.

35. Vandenberk B, Vandael E, Robyns T, Vandenberghe J, Garweg C, Foulon V, et al. Which QT correction formulae to use for QT monitoring? J Am Heart Assoc. 2016:5:e003264.

36. Viskin S, Rosovski U, Sands AJ, Chen E, Kistler PM, Kalman JM, et al. Inaccurate electrocardiographic interpretation of long QT: the majority of physicians cannot recognize a long QT when they see one. Hear Rhythm. 2005;2:569-74.

37. Postema PG, De Jong JSSG, Van der Bilt IAC, Wilde AAM. Accurate electrocardiographic assessment of the QT interval: teach the tangent. Hear Rhythm. 2008;5:1015-8.

38. Bexton RS, Vallin HO, Camm AJ. Diurnal variation of the QT interval-influence of the autonomic nervous system. Br Heart J. 1986;55:253-8.

\section{Publisher's Note}

Springer Nature remains neutral with regard to jurisdictional claims in published maps and institutional affiliations.
Ready to submit your research? Choose BMC and benefit from:

- fast, convenient online submission

- thorough peer review by experienced researchers in your field

- rapid publication on acceptance

- support for research data, including large and complex data types

- gold Open Access which fosters wider collaboration and increased citations

- maximum visibility for your research: over 100M website views per year

At BMC, research is always in progress.

Learn more biomedcentral.com/submissions 